\title{
Synthesis, in-vitro antioxidant activity and in-silico prediction of drug-likeness properties of a novel compound: 4-(3,5-Di-tert-butyl- 4-hydroxybenzylidene)-3-methylisoxazol-5(4H)-one
}

\author{
Madhavi Kuchana*, Durga Rani Bethapudi, Ragini Katamarajugari Ediga, Yoshitha Sisapuram \\ Institute of Pharmaceutical Technology, Sri Padmavati Mahila Visvavidyalayam Womens University Tirupati, Tirupati, India.
}

\section{ARTICLE INFO \\ Received on: $12 / 05 / 2019$ \\ Accepted on: 22/07/2019 \\ Available online: 01/09/2019}

\section{Key words:}

Butylated hydroxytoluene,

2,6-Di-tert-butylphenol,

4-Substituted benzylidene-3methylisoxazol-5(4H)-one,

In-vitro antioxidant activity, In-silico prediction.

\begin{abstract}
A simple and eco-friendly method has been used for the synthesis of novel compound 4-(3,5-di-tert-butyl-4hydroxybenzylidene)-3-methylisoxazol-5(4H)-one. The synthesized compound was characterized by its physical and spectral data. This compound was screened for in-vitro antioxidant activity by 1,1-diphenyl-2-picrylhydrazyl (DPPH) and nitric oxide free radical scavenging assays at $100 \mu \mathrm{M}$ concentration. The DPPH scavenging ability of evaluated compound was superior to the synthetic antioxidant butylated hydroxytoluene (BHT) and comparable to the standard ascorbic acid. The nitric oxide scavenging ability of the compound was also found greater than the BHT. The in silico prediction of molecular properties and bioactivity scores of synthesized compound and BHT were carried out using Molinspiration Cheminformatics online software. The study revealed that the predicted compounds obeyed Lipinski's rule of five and showed good intestinal absorption and membrane permeability indicating the drug-likeness properties of predicted compounds. Finally, the in silico study identified the title compound as a nuclear receptor ligand compared to BHT.
\end{abstract}

\section{INTRODUCTION}

Butylated hydroxytoluene (BHT), a synthetic antioxidant primarily used as a preservative in food, pharmaceuticals, and cosmetics. It can be used as an antioxidant in many industrial products and laboratory chemicals. It has several other names, which include 3,5-di-tert-butyl-4-hydroxytoluene, 2,6-di-tertbutyl-p-cresol, 2,6-di-tert-butyl-4-methylphenol, and Ionol. Generally, it can be prepared from $p$-cresol by dibutylation or from 2,6-di-tert-butylphenol by aminomethylation or hydroxymethylation followed by hydrogenolysis. Various synthetic derivatives containing BHT or 2,6-di-tert-butylphenol moiety such as chalcones (Cabral et al., 2017; Won et al., 2005), hydrazones (Cuadro et al., 1998; Duarte et al. 2007; Podyachev et al., 2012), styryl heterocycles (Flynn et al., 1991; Lazer et al., 1989;

"Corresponding Author

Madhavi Kuchana, Institute of Pharmaceutical Technology, Sri Padmavati Mahila Visvavidyalayam Women s University Tirupati, Tirupati, India.

E-mail: kuchanamadhavi@yahoo.co.in
Kelarev et al., 2003; Madhavi et al., 2010; Mullican et al., 1993), benzylidene compounds (Clemens et al., 1991; Hori et al., 2002; Ikuta et al., 1987; Inagaki et al., 2000; Katsumi et al., 1986; Phillips et al., 1992; Unangst et al., 1994; Wong et al., 1992), and other heterocyclic systems (Gowdra et al., 2014; Isomura et al., 1983a; 1983b; 1984; Jeong et al., 2004; Unangst et al., 1992; Ziakas et al., 2006) were reported to have anti-inflammatory activity with dual inhibition of 5-lipoxygenase and cyclooxygenase enzymes as well as low ulcerogenic liability. Several of these compounds were also reported to have anti-obesity, anti-tumor, and antioxidant activities. The drugs containing BHT or 2,6-di-tert-butylphenol were available commercially, which include Tazofelone $\mathbb{R}$, Darbufelone $\AA$, Prifelone $\AA$, and Tebufelone $\AA$ used to treat inflammatory conditions and Eldacimibe ${ }^{\circledR}$ used for the treatment of hyperlipidemia.

Isoxazol-5(4H)-one belongs to the class of fivemembered heterocyclic compound and known to possess a variety of biological and pharmacological activities (Ishioka et al., 2003; Kafle and Cho, 2012; Laughlin et al., 2005; Srikantamurthy et al., 2018). Especially, 4-substituted benzylidene-3-methylisoxazol- 
$5(4 H)$-ones were utilized as versatile building blocks for the synthesis of fused heterocycles (Soliman et al., 2013). In the literature, the synthesis of 4-substituted benzylidene-3methylisoxazol-5(4H)-ones was reported through a one-pot reaction of ethyl acetoacetate with hydroxylamine hydrochloride and substituted benzaldehyde using different reagents, catalysts, and/or reaction medium (Chavan et al., 2014; Vekariya and Patel, 2017). However, no research reports found regarding the preparation of 4-(3,5-di-tert-butyl-4-hydroxybenzylidene)-3methylisoxazol-5(4H)-one. Hence, the present study aimed to prepare the title compound and to evaluate preliminarily its in vitro antioxidant properties.

A number of computational techniques to identify drug-like molecules were developed in recent years (Kadam and Roy, 2007). Molinspiration Cheminformatics software, a free online service (https://www.molinspiration.com) used for the computational prediction of molecular properties (Molinspiration property engine v2018.10) such as $\log p$, polar surface area, molecular weight, hydrogen bond donors, hydrogen bond acceptors and others, as well as bioactivity score (Molinspiration bioactivity score v2018.03) as GPCR ligand, ion channel modulator, kinase inhibitor, nuclear receptor ligand, protease inhibitor, and enzyme inhibitor. Therefore, the present study also aimed to evaluate druglikeness properties of the title compound using Molinspiration Cheminformatics software.

\section{MATERIALS AND METHODS}

\section{Reagents and Instruments}

3,5-Di-tert-butyl-4-hydroxybenzaldehyde was procured from Alfa Aesar, and all other chemicals were obtained from Sigma Aldrich and SD fine chemicals. The melting points were determined in open capillaries on tempo melting point apparatus and they were uncorrected. The purity of compounds was checked by thin-layer chromatography using the glass plates coated with silica gel-G and spots were detected by iodine vapor. The IR spectrum was recorded using $\mathrm{KBr}$ Pellet on a BRUKER Infrared spectrophotometer $\left(\mathrm{cm}^{-1}\right)$. ${ }^{1} \mathrm{H}$ NMR and ${ }^{13} \mathrm{C}$ NMR spectra were recorded on BRUKER NMR spectrometers (400 $\mathrm{MHz}$ for 1 $\mathrm{H}$ NMR and $100 \mathrm{MHz}$ for 13C NMR) and the chemical shifts expressed as $\delta$ values (ppm) downfield from tetramethylsilane as an internal standard. The mass spectrum was recorded on LCMS, Agilent Technology 1200 infinity series, Apex chromatogram model.

\section{Synthesis of 4-(3,5-di-tert-butyl-4-hydroxybenzylidene)-3- methylisoxazol-5(4H)-one ( $\mathrm{V}$, Scheme- I)}

To a solution of $0.139 \mathrm{gm}(0.002 \mathrm{~mol})$ of hydroxylamine hydrochloride (I) in $2 \mathrm{ml}$ of absolute alcohol, added $0.164 \mathrm{gm}$ $(0.002 \mathrm{~mol})$ of anhydrous sodium acetate and $0.25 \mathrm{ml}(0.002 \mathrm{~mol})$ of ethyl acetoacetate (II). The reaction contents were stirred for 1 hour to give an oxime initially, followed by its cyclization to form an intermediate 3-methylisoxazol-5(4H)-one (III). The formation of intermediate compound III was confirmed by TLC. To the above reaction mixture, added $0.468 \mathrm{gm}(0.002 \mathrm{~mol})$ of 3,5-di-tertbutyl-4-hydroxybenzaldehyde (IV) and the reaction contents were refluxed for 1 hour. The completion of the reaction was monitored by TLC. Then the solution was cooled and the crude product
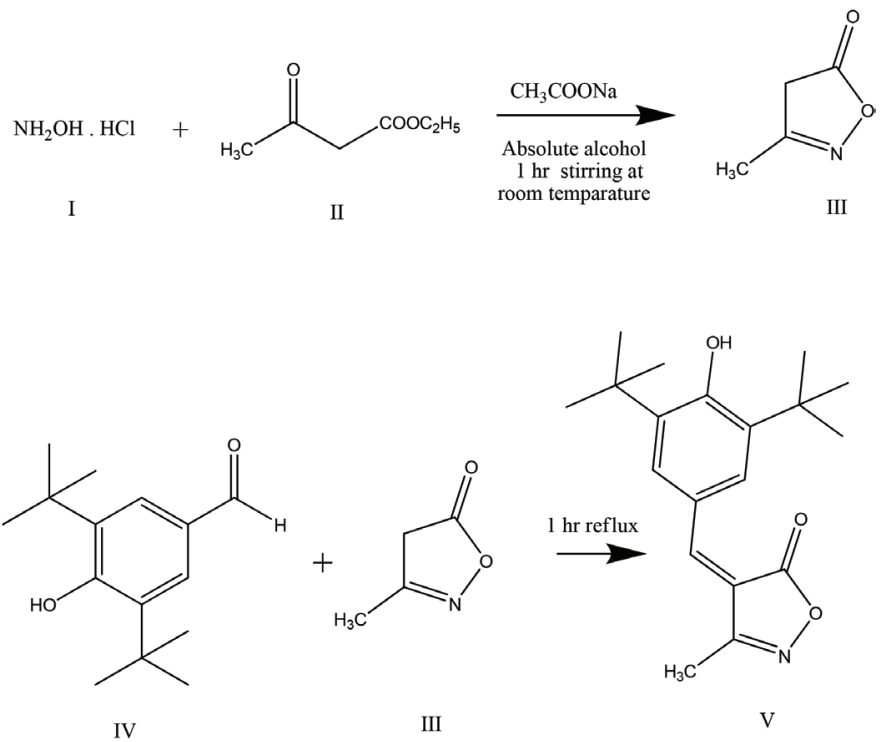

Scheme I. Synthesis of 4-(3,5-di-tert-butyl-4-hydroxybenzylidene)-3methylisoxazol-5(4H)-one (V).

obtained was collected by filtration. Finally, recrystallization of the crude compound with aqueous alcohol resulted in a bright yellowish crystalline powder. Yield $72 \%$; m.p $200^{\circ} \mathrm{C}-202^{\circ} \mathrm{C}$; IR $\left(\mathrm{KBr}, \mathrm{cm}^{-1}\right) v_{\max }: 3615$ (O-H stretch, free), 3446 (O-H stretch, bonded), 3116 (Ar C-H stretch), 2961, 2922 (Ali C-H stretch), $1742(\mathrm{C}=\mathrm{O}$ stretch $), 1616(\mathrm{C}=\mathrm{N}$ stretch $), 1569(\mathrm{C}=\mathrm{C}$ stretch $)$, 1218, 1118 (C-O stretch), 812 (C-H def); ${ }^{1} \mathrm{H}$ NMR (DMSO- $\left.d_{6}\right)$ $\delta$ ppm: $1.43\left(\mathrm{~s}, 18 \mathrm{H},-\mathrm{C}\left(\mathrm{CH}_{3}\right)_{3}\right), 2.27\left(\mathrm{~s}, 3 \mathrm{H},-\mathrm{CH}_{3}\right), 7.87(\mathrm{~s}, 1 \mathrm{H}$, $-\mathrm{CH}=), 8.41$ (s, br, 1H, OH), $8.46(\mathrm{~s}, 2 \mathrm{H}, \mathrm{Ar}-\mathrm{H}) \mathrm{ppm} ;{ }^{13} \mathrm{C} \mathrm{NMR}$ $\left(\mathrm{DMSO}-d_{6}\right) \delta$ ppm: $168.9(\mathrm{C}=\mathrm{O}), 162.3(\mathrm{C}=\mathrm{N}), 160.7(\mathrm{C}-\mathrm{OH})$, $152.8(\mathrm{CH}=$ benzylidene $), 138.4\left(2 \mathrm{C} \underline{\mathrm{C}}-\mathrm{C}\left(\mathrm{CH}_{3}\right)_{3}\right.$ Aromatic $), 132.8$ $(\underline{\mathrm{C}}-\mathrm{CH}=$ Aromatic $), 124.8(\underline{\mathrm{C}}=\mathrm{CH}$ isoxazole $), 113.8$ (2C Ar), 34.7 $\left(2 \mathrm{C}-\underline{\mathrm{C}}\left(\mathrm{CH}_{3}\right)_{3}\right), 30.0\left(6 \mathrm{C}-\mathrm{C}\left(\underline{\mathrm{CH}}_{3}\right)_{3}\right), 11.3\left(\mathrm{CH}_{3}\right.$ isoxazole $) ; \mathrm{MS}$ $\mathrm{m} / \mathrm{z}: 314\left(100 \%, \mathrm{M}^{-} \mathrm{H}^{-}\right)$.

\section{In-vitro antioxidant activity}

\section{DPPH free radical scavenging assay}

To the test compound in absolute alcohol $(100 \mu \mathrm{M})$, freshly prepared DPPH solution in absolute alcohol $(100 \mu \mathrm{M})$ was added and the solution kept at room temperature for 20 minutes and the absorbance measured at $517 \mathrm{~nm}$ (Blois, 1958). The control experiment carried out in a similar manner without the test compound. The standard compounds ascorbic acid and BHT were used as positive controls for comparing the results. The results were expressed as the average of triplicate measurements. The percentage of the DPPH radical scavenging was calculated using the following formula.

Percentage of DPPH radical scavenging $=\frac{(\text { Control }- \text { Test })}{\text { Control }} \times 100$

Nitric oxide free radical scavenging assay

Sodium nitroprusside $(5 \mathrm{mM})$ in phosphate-buffered saline was added to $100 \mu \mathrm{M}$ concentration of test compound dissolved in alcohol and incubated at $25^{\circ} \mathrm{C}$ for 150 minutes. 
The control experiment was carried out in a similar manner without test compound but with an equal amount of solvent. The standard BHT was used as a positive control for comparison. After incubation, $2 \mathrm{ml}$ of incubated solution was added to $2 \mathrm{ml}$ of Griess reagent ( $1 \%$ Sulfanilamide, $2 \% \mathrm{H}_{3} \mathrm{PO}_{4}$, and $0.1 \% \mathrm{~N}-(1-$ Naphthyl)ethylenediamine dihydrochloride). The absorbance of chromophore formed during the diazotization of nitrite with sulfanilamide and subsequent coupling with N-(1-Naphthyl) ethylenediamine was read at $546 \mathrm{~nm}$ (Sreejayan and Rao, 1997). The percentage of the nitric oxide free radical scavenging was calculated using the following formula.

Percentage of nitric oxide scavenging $=\frac{(\text { Control }- \text { Test })}{\text { Control }} \times 100$

Prediction of molecular properties and bioactivity score of 4-(3,5-Di-tert-butyl-4-hydroxybenzylidene)-3-methylisoxazol5(4H)-one using Molinspiration Cheminformatics software

The Molinspiration Cheminformatics online molecular property calculation toolkit was used to know the drug-likeness of the synthesized compound and standard BHT based on Lipinski's rule of five. The structures of the title compound and standard BHT were generated and their molecular properties such as $\log P$ value, molecular weight, Topological Polar Surface Area (TPSA), hydrogen bond acceptor/donor, rotatable bonds, and molecular volume were calculated for the prediction of absorption, distribution, metabolism, and elimination properties. Percentage of absorption of the compounds was estimated using the following equation: \%ABS $=109-(0.345$ X TPSA $)$ (da Silva et al., 2015). The bioactivity scores of the synthesized compound and BHT as GPCR ligands, ion channel modulators, kinase inhibitors, nuclear receptor ligands, protease inhibitors, and enzyme inhibitors were also predicted using the same Molinspiration Cheminformatics software.

\section{RESULTS AND DISCUSSION}

\section{Chemistry}

In the present research work, a novel compound 4-(3,5-ditert-butyl-4-hydroxybenzylidene)-3-methylisoxazol-5(4H)-one (V) was synthesized by condensation of active methylene group of 3-methylisoxazol-5(4H)-one (III) with 3,5-di-tert-butyl-4hydroxybenzaldehyde (IV). The intermediate 3-methylisoxazol$5(4 H)$-one (III) was generated by stirring equivalent amounts of hydroxylamine hydrochloride (I) and ethyl acetoacetate (II) in alcohol (Cocivera et al., 1976; Wazalwar et al., 2017) containing equimolar quantity of sodium acetate and the resultant intermediate was utilized for the next step without isolation. The acetic acid generated during the preparation of 3-methylisoxazol$5(4 H)$-one (III) acts as a catalyst in the condensation reaction. Hence, this reaction may be considered as an eco-friendly and simple synthetic method. The yield of the synthesized compound was good and found to be $72 \%$. Furthermore, it was characterized by physical and spectral analytical data.

The IR spectrum of the compound V showed absorption bands at 3615 and $3446 \mathrm{~cm}^{-1}$ due to free as well as bonded $\mathrm{O}-\mathrm{H}$ stretching vibrations. The absorption bands due to aromatic $\mathrm{C}-\mathrm{H}$ stretching vibrations appeared at $3116 \mathrm{~cm}^{-1}$ and the aliphatic stretching vibrations appeared at 2961 and $2922 \mathrm{~cm}^{-1}$. The absorption band due to $\alpha, \beta$ unsaturated carbonyl group appeared at $1742 \mathrm{~cm}^{-1}$. The spectrum also revealed the presence of absorption bands at 1616 and $1569 \mathrm{~cm}^{-1}$ due to $\mathrm{C}=\mathrm{N}$ and $\mathrm{C}=\mathrm{C}$ stretching, respectively. The ${ }^{1} \mathrm{H}$ NMR spectrum of the compound $\mathrm{V}$ revealed the presence of more intense singlet peak at $\delta 1.43$ due to 18 protons of the di-tert-butyl group. A singlet at $\delta 2.27$ indicates the protons of the methyl group of isoxazole ring. The benzylidene proton and aromatic protons appeared as two different singlets at $\delta$ 7.87 and $\delta 8.46$. The phenolic proton appeared as a broad singlet at $\delta$ 8.41. The ${ }^{13} \mathrm{C}$ NMR spectrum of compound $\mathrm{V}$ showed assignable peaks at $\delta 168.9, \delta 162.3, \delta 160.7, \delta 152.8, \delta 138.4(2 \mathrm{C}), \delta 132.8$, $\delta 124.8, \delta 113.8(2 \mathrm{C}), \delta 34.7(2 \mathrm{C}), \delta 30.0(6 \mathrm{C})$, and $\delta 11.3 \mathrm{ppm}$. The mass spectrum of the compound V showed characteristic [M$\mathrm{H}]$ at 314 . These spectral analytical data confirm the structure of the title compound.

\section{In-vitro antioxidant activity}

In the present study, the synthesized compound was evaluated preliminarily for in-vitro antioxidant property as it contains the synthetic antioxidant BHT in its structure. Two different models, DPPH and nitric oxide free radical scavenging assays, were selected for screening the antioxidant potential of compound $\mathrm{V}$ at $100 \mu \mathrm{M}$ concentration. The activity data were presented in Table 1. The scavenging of DPPH free radical by compound V was $84.64 \%$, near to the value found with the standard compound ascorbic acid (87.15\%). Furthermore, the DPPH free radical scavenging ability of compound $\mathrm{V}$ appeared greater than the standard compound BHT (55.17\%). The compound V also showed better activity in scavenging nitric oxide free radical (57.71\%) when compared with the standard BHT (38.19\%). The greater activity of compound $\mathrm{V}$ may be due to the cyclic $\alpha, \beta$ unsaturated carbonyl system formed by linkage of BHT moiety to 3-methylisoxazol-5(4H)-one at 4-position. This observation was in confirmation with our previous report, that the $\alpha$-cyano$\mathrm{N}$-(4-hydroxyphenyl)cinnamamide with BHT moiety/3,5 di-tertbutyl-4-hydroxy substitution exhibited good radical scavenging properties (Madhavi et al., 2019).

Prediction of molecular properties and bioactivity score of 4-(3,5-Di-tert-butyl-4-hydroxybenzylidene)-3-methylisoxazol5(4H)-one using Molinspiration Cheminformatics software

The molecular properties of the synthesized compound and the reference compound BHT were calculated using Molinspiration Cheminformatics software. The data were presented in Table 2. The predicted data revealed that both the compounds obeyed the Lipinski's rule of five; thus, indicated their drug-likeness. However, the $\log P$ value of compound $\mathrm{V}$ was found 4.66 , within the acceptable criteria $(\log p \leq 5)$, whereas

Table 1. In vitro antioxidant activity of 4-(3,5-di-tert-butyl-4hydroxybenzylidene)-3-methylisoxazol-5(4H)-one (V).

\begin{tabular}{clcc}
\hline Sl. no & Compound & $\begin{array}{c}\text { \% Scavenging of DPPH } \\
\text { at } \mathbf{1 0 0} \boldsymbol{\mu} \mathbf{M}\end{array}$ & $\begin{array}{c}\text { \% Scavenging of nitric } \\
\text { oxide at } \mathbf{1 0 0} \boldsymbol{\mu M}\end{array}$ \\
\hline 1 & V & 84.64 & 57.71 \\
2 & BHT & 55.17 & 38.19 \\
3 & Ascorbic acid & 87.15 & - \\
\hline
\end{tabular}


the $\log P$ value of standard compound BHT was 5.43. The $\log \mathrm{P}$ measurement used to understand the substance solubility behavior and hence their oral absorption and bioavailability. The compound $\mathrm{V}$ possesses an adequate number of hydrogen bond acceptors $(\mathrm{HBA}=4)$ and hydrogen bond donor $(\mathrm{HBD}=1)$, ensuring efficient interaction with hydrogen bonding groups of the receptor. The number of rotatable bonds found with compound $\mathrm{V}$ was 3, indicating the conformational flexibility when compared with BHT. The computational TPSA value of compound V was found $63.33 \AA^{2}$ and \%ABS was $87.15 \%$ indicative of good intestinal absorption and membrane permeability, thus encouraging its use as a new drug candidate.

Prediction of bioactivity scores of synthesized compound and BHT was performed by Molinspiration Cheminformatics software and the data presented in Table 3. As a general rule, the larger the bioactivity score, higher the probability that the predicted compound would be active. Therefore, a molecule having bioactivity score more than 0.00 expected to possess considerable biological activities, while the values between -0.50 and 0.00 considered to be moderately active and the score less than -0.50 presumed to be inactive (Verma, 2012). The results of in-silico prediction indicated that the compound $\mathrm{V}$ was more active as nuclear receptor ligand compared to standard compound BHT. Furthermore, the bioactivity score of compound V as nuclear receptor ligand was found more than the previously synthesized and predicted compound containing 3,5-di-tert-butyl-4-hydroxy substitution on the phenyl ring of $\alpha$-cyano-N-(2-hydroxyphenyl) cinnamamide (Madhavi and Renuka, 2018). The higher predictive bioactivity score of the compound $\mathrm{V}$ as nuclear receptor ligand may be attributed to the overall estimated TPSA value of the

Table 2. Molecular properties prediction of 4-(3,5-di-tert-butyl-4hydroxybenzylidene)-3-methylisoxazol-5(4H)-one (V) using molinspiration cheminformatics software.

\begin{tabular}{clcc}
\hline Sl. no & Molecular properties & Compound V & BHT \\
\hline 1 & miLogP & 4.66 & 5.43 \\
2 & Molecular weight & 315.41 & 220.36 \\
3 & Hydrogen bond acceptor (HBA) & 4 & 1 \\
4 & Hydrogen bond donor (HBD) & 1 & 1 \\
5 & Molecular volume & 308.80 & 241.00 \\
6 & Number of violations (n Violations) & 0 & 1 \\
7 & Number of rotatable bonds (n rotb) & 3 & 2 \\
8 & Molecular polar surface area (TPSA) & 63.33 & 20.23 \\
9 & Percentage of absorption (\%ABS) & 87.15 & 102.02 \\
\hline
\end{tabular}

Table 3. Bioactivity score prediction of 4-(3,5-di-tert-butyl-4hydroxybenzylidene)-3-methylisoxazol-5(4H)-one (V) using molinspiration cheminformatics software.

\begin{tabular}{clcc}
\hline Sl. no. & Bioactivity score & Compound V & BHT \\
\hline 1 & GPCR ligand & -0.45 & -0.34 \\
2 & Ion channel modulator & -0.59 & 0.00 \\
3 & Kinase inhibitor & -0.15 & -0.48 \\
4 & Nuclear receptor ligand & 0.34 & -0.08 \\
5 & Protease inhibitor & -0.50 & -0.57 \\
6 & Enzyme inhibitor & -0.30 & -0.07 \\
\hline
\end{tabular}

molecule and other molecular properties, mainly hydrogen bond characteristics, hydrophobicity, electronic distribution, molecule size, and flexibility. In addition, the presence of pharmacophoric groups and/or structural similarity with the training set molecules may also contribute to the predictive high bioactivity score as nuclear receptor ligand.

\section{CONCLUSION}

4-(3,5-Di-tert-butyl-4-hydroxybenzylidene)-3methylisoxazol-5(4H)-one, a novel isoxazol-5(4H)-one derivative containing sterically hindered phenolic moiety BHT, was successfully synthesized with good yield and purity by cyclocondensation of ethyl acetoacetate and hydroxylamine hydrochloride in the presence of sodium acetate followed by subsequent condensation of resultant 3-methylisoxazol-5(4H)one with 3,5-di-tert-butyl-4-hydroxybenzaldehyde. The in-vitro antioxidant study revealed that the title compound possesses extremely good DPPH free radical scavenging ability comparable to the standard compound ascorbic acid and greater than the BHT. The title compound also exhibited good nitric oxide scavenging ability better than the BHT. The better in-vitro antioxidant properties of compound $\mathrm{V}$ indicates the structural importance of 3,5-di-tert-butyl-4-hydroxybenzylidene moiety conjugating to the carbonyl group of 3-methylisoxazol-5(4H)-one. Since the title compound exhibited better in-vitro antioxidant activity, it can be further investigated against the diseases associated with oxidative stress and inflammation.

The in-silico prediction of molecular properties of the synthesized compound and the standard BHT revealed that these compounds obeyed Lipinski's rule of five and showed good intestinal absorption as well as membrane permeability indicating the drug-likeness properties. In addition, the bioactivity score prediction identified the title compound as the most promising nuclear receptor ligand compared to the standard BHT. Therefore, further studies needed to be performed to know the safety and therapeutic efficacy of the title compound.

\section{ACKNOWLEDGMENTS}

The Authors thank the DST-CURIE Centre, Sri Padmavati Mahila Visvavidyalayam (Women's University) for providing IR spectrum and Laila Impex R \& D Centre, Vijayawada, Andhra Pradesh, for providing ${ }^{1} \mathrm{H} \mathrm{NMR},{ }^{13} \mathrm{C} \mathrm{NMR}$, and Mass spectra.

\section{CONFLICT OF INTEREST}

The authors declare that there is no conflict of interest.

\section{REFERENCES}

Blois MS. Antioxidant determination by the use of stable free radical. Nature, 1958; 181:119-20.

Cabral BLS, da Silva ACG, de Avila RI, Cortez AP, Luzin RM, Liao LM, de Souza Gil E, Sanz G Vaz BG, Sabino JR, Menegatti R, Valadares MC. A novel chalcone derivative, LQFM064, induces breast cancer cell death via p53, p21, KIT and PDGFRA. Eur J Pharm Sci, 2017; 107:1-15.

Chavan AP, pinjari AB, Mhaske PC. An efficient synthesis of 4-arylmethylidene-3-substituted-isoxazol-5(4H)-ones in aqueous medium. J Heterocyclic Chem, 2014; 52(6):1911-5.

Cocivera M, Effio A, Chen HE, Vaish S. Reaction of hydroxylamine with ethyl acetoacetate. Details of the addition and 
cyclization steps studied by flow nuclear magnetic resonance. J Am Chem Soc, 1976; 98(23):7362-6.

Cuadro AM, Valenciano J, Vaquero JJ, Alvarez-Builla J Sunkel C Casa-Juana MF, Orttega MP. Synthesis and biological evaluation of 2,6-di-tert-butylphenol hydrazones as 5-lipoxygenase inhibitors. Bioorg Med Chem, 1998; 6:173-80.

Clemens JA, Ho PPK, Panetta JA. LY178002 Reduces rat brain damage after transient global forebrain ischemia. Stroke, 1991; 22(8):1048-52.

da Silva MM, Comin M, Duarte TS, Foglio MA, de Carvalho JE, Vieira MC, Formagio ASN. Synthesis, antiproliferative activity and molecular properties predictions of galloyl derivatives. Molecules 2015; 20(4):5360-73.

Duarte CD, Tributino JL, Lacerda DI, Martins MV, AlexandreMoreira MS, Dutra F, Bechara EJ, De-Paula FS, Goulart MO, Ferreira J, Calixto Jb, Nunes MP, Bertho AL, Miranda AL, Barreiro EJ, Fraga CA. Synthesis, pharmacological evaluation and electrochemical studies of novel 6-nitro-3,4-methylenedioxyphenyl-N-acylhydrazone derivatives: discovery of LASSBio-881, a new ligand of cannabinoid receptors. Bioorg Med Chem, 2007; 15(6):2421-33.

Flynn DL, Belliotti TR, Boctor AM, Connor DT, Kostlan CR, Nies DE, Ortwine DF, Schrier DJ, Sircar JC. Styrylpyrazoles, Styrylisoxazoles and Styrylisothiazoles. Novel 5-lipoxygenase and cyclooxygenase inhibitors. J Med Chem, 1991; 34:518-25.

Gowdra VS, Mudgal J, Bansal P, Nayak PG, Reddy SAM, Shenoy GG, Valiathan M, Chamallamudi MR, Nampurath GK. Synthesis, characterization and preclinical evaluation of new thiazolidin-4-ones substituted with p-chlorophenoxy acetic acid and clofibric acid against insulin resistance and metabolic disorders. Biomed Res Int, 2014; Article ID 620434, 1-14.

Hori H, Nagasawa H, Ishibasi M, Uto Y, Hirata A, Saijo K, Ohkura K, Kirk KL, Uehara Y. An antitumor 2-hydroxyarylidene-4cyclopentene-1,3-dione as a protein tyrosine kinase inhibitor having low mitochondrial toxicity. Bioorg Med Chem, 2002; 10(10):3257-65.

Ikuta H, Shirota H, Kobayashi Y, Yamagishi K, Yamada L, Yamotsu I, Katayama K. Synthesis and anti-inflammatory activity of 3-(3,5-di-tert-butyl-4-hydroxybenzylidene)pyrrolidin-2-ones. J Med Chem, $1987 ; 30: 1995-8$

Inagaki M, Tsuri T, Jyoyama $\mathrm{H}$, Ono T, Yamada K Kobayashi M, Hori Y, Arimura A, Yasui K, Ohno K, Kakudo S, Koizumi K, Suzuki R, Kato M, Kawai S, Matsumito S. Novel antiarthritic agents with 1,2-isothiazolidine-1,1-dioxide ( $\gamma$-sultam) skeleton: cytokine suppressive dual inhibitors of cyclooxygenase-2 and 5-lipoxygenase. J Med Chem, $2000 ; 43: 2040-8$.

Ishioka T, Tanatani A, Nagasava K, Hashimoto Y. Anti-androgens with full antagonistic activity toward human prostate tumor LNCaP cells with mutated androgen receptor. Bioorg Med Chem Lett 2003; 13:2655-8.

Isomura $\mathrm{Y}$, Ito N, Homma H, Abe T, Kubo K. Studies on the synthesis and anti-inflammatory activity of 2,6-di-tert-butylphenols with a heterocyclic group at the 4-position. I. Chem Pharm Bull, 1983a; 31(9):3168-78.

Isomura $\mathrm{Y}$, Ito $\mathrm{N}$, Sakamoto $\mathrm{S}$, Homma $\mathrm{H}$, Abe $\mathrm{T}$, Kubo $\mathrm{K}$. Studies on the synthesis and anti-inflammatory activity of 2,6-di-tertbutylphenols with a heterocyclic group at the 4-position. II. Chem Pharm Bull, 1983b; 31(9):3179-85.

Isomura $\mathrm{Y}$, Sakamoto S, Ito N, Homma $\mathrm{H}$, Abe T, Kubo K. Synthesis and anti-inflammatory activity of 2,6-di-tert-butylphenols with a heterocyclic group at the 4-position. III. Chem Pharm Bull, 1984; 32(1):152-65.

Jeong TS, Kim KS, Kim JR, Cho KH, Lee S, Lee WS. Novel 3,5-diaryl pyrazolines and pyrazole as low density lipoprotein (LDL) oxidation inhibitor. Bioorg Med Chem Lett, 2004; 14(11):2719-23.

Kadam RU, Roy N. Recent trends in drug likeness prediction: a comprehensive review of in silico methods. Indian J Pharm Sci, 2007; 69(5): 609-15.

Kafle B, Cho H. Isoxazolone derivatives as potent inhibitors of PTP1B. Bull Korean Chem Soc, 2012; 33(1):275-7.
Katsumi I, Kondo H, Fuse Y, Yamashita K, Hidaka T, Hosoe K, Takeo K, Yamashita T, Watanabe K. Studies on Styrene Derivatives. II. Synthesis and antiinflammatory activity of 3,5-di-tert-butyl-4 hydroxystyrenes. Chem Pharm Bull, 1986; 34(4):1619-27.

Kelarev VI, Silin MA, Borisova OA. Synthesis of derivatives of $\Delta 2$-imidazoline-5-one and imidazolidine containing residues of strericallyhindered phenols. Chem Heterocycl Compd, 2003; 39(6):729-35.

Lazer ES, Wong HC, Possanza GJ, Graham AG, Farina PR Antiinflammatory 2,6-Di-tert-butyl-4-(2-arylethenyl)phenols. J Med Chem, 1989; 32(1): 100-4

Laughlin SK, Clark MP, Djung JF, Golebiowski A, Brugel TA, Sabat M, Bookland RG, Laufersweiler MJ, VanRens JC, Townes JA, De B, Hsieh LC, Xu SC, Walter RL, Mekel MJ, Janusz MJ. The development of new isoxazolone based inhibitors of tumor necrosis factor- alpha (TNF- $\alpha$ ) production. Bioorg Med Chem Lett, 2005; 15(9):2399-403.

Madhavi K, Bharathi K, Prasad KVSRG. Synthesis and evaluation of 3-methyl-4-nitro-5-(substituted styryl)isoxazoles for antioxidant and anti-inflammatory activities. Res J Pharm Biol Chemi Sci, 2010; 1(4):1073-82.

Madhavi K, Renuka K. Synthesis and evaluation of novel $\alpha$-cyano-N-(2-hydroxyphenyl)cinnamamides for antioxidant, antibacterial and anti-inflammatory activities: In silico prediction of drug likeness properties. Int J Pharm Res, 2018; 10(3):300-10.

Madhavi K, Swathi K, Anitha B, Reddy Usha Sree G, Sravanthi G, Ashwini G. Synthesis and evaluation of $\alpha$-cyano-N-(4-hydroxyphenyl) cinnamamides for antioxidant, anti-inflammatory activities: In-silico prediction of drug likeness properties. Int J Pharm Sci Res, 2019, 10(1):203-13

Mullican MD, Wilson MW, Connor DT, Kostlan CR, Schrier DJ, Dyer RD. Design of 5-[3,5-bis(1,1-dimethylethyl)-4-hydroxyphenyl]1,3,4-thiadiazole, -1,3,4-oxadiazoles and 1,2,4-triazoles as orally active, nonulcerogenic antiinflammatory agents. J Med Chem, 1993; 36:1090-9.

Phillips ML, Berry DM, Panetta JA. Kinetic resolution of a racemic sulfide by enantioselective sulfoxide formation. J Org Chem, 1992; 57(14):4047-9.

Podyachev SN, Barsukova TA, Bukharov SV, Syakaev VV, Sudakova SN, Nugumanova GN, Konovalov AI. Synthesis of hydrazones containing sterically hindered phenol groups and tetrathiacalix[4]arene fragment. Russ J Org Chem, 2012; 48(10):1360-5.

Soliman HA, Morsy EMH, Sayed HH, Elwahed NAMMA. Synthesis and reactions of isoxazole derivative for biological evaluation. Open J Org Chem, 2013; 1(3):33-40.

Sreejayan, Rao MNA. Nitric oxide scavenging by curcuminoids. J Pharm Pharmcol, 1997; 49:105-7.

Srikantamurthy N, Vrushabendra B, Chandra, Chetan J, Shridevi D. Solvent free synthesis of (E)-4-benzylidene-3-methylisoxazol-5(4H)ones and their cytotoxic screening against MCF7 cell line. J Applicable Chem, 2018; 7(6):1582-91.

Unangst PC, Connor DT, Cetenko WA, Sorenson RJ, Kostlan CR, Sircar JC, Wright CD Schrier DJ, Dyer RD. Synthesis and biological evaluation of 5-[[3,5-bis(1,1-dimethylethyl)-4-hydroxyphenyl] methylene]oxazoles, -thiazoles and -imidazoles: Novel dual inhibitors of 5-lipoxygenase and cyclooxygenase inhibitors with anti-inflammatory activity. J Med Chem, 1994; 37:322-8.

Unangst PC, Shrum GP, Connor DT, Dyer RD, Schrier DJ. Novel 1,2,4-Oxadiazoles and 1,2,4-thiadiazoles as dual 5-lipoxygenase and cyclooxygenase inhibitor. J Med Chem, 1992; 35:3691-8.

Vekariya RH, Patel HD. Facile, eco-friendly and one-pot synthesis of 3,4-disubstituted isoxazol-5(4H)-ones using starch solution as a reaction media. Indian J Chem, 2017; 56B(8):890-6.

Verma A. Lead finding from phyllanthus debelis with hepatoprotective potentials, Asian Pac J Trop Biomed, 2012; 1:735-7.

Wazalwar SS, Banpurkar AR, Perdih F. Aqueous phase synthesis, crystal structure and biological study of isoxazole extensions of pyrazole-4carbaldehyde derivatives. J Mol Struct, 2017; 1150:258 — 67.

Won SJ, Liu CT, Tsao LT, Wenq JR, Ko HH, Wang JP, Lin 
CN. Synthetic chalcone as potential anti-inflammatory and cancer chemopreventive agents. Eur J med Chem, 2005; 40(1):103-12.

Wong S, Lee SJ, Frierson III MR, Proch J, Miskowski TA, Rigby

BS, Schmolka SJ, Naismith RW, Kreutzer DC, Lindquist R. Antiarthritic profile of BF-389 - a novel anti-inflammatory agent with low ulcerogenic liability. Agents Actions, 1992; 37(1-2):90-8.

Ziakas GN, Rekka EA, Gavalas AM, Eleftheriou PT, Kourounakis PN. New analogs of butylated hydroxytoluene as anti-inflammatory and antioxidant agents. Bioorg Med Chem, 2006; 14(16):5616-24.
How to cite this article:

Kuchana M, Bethapudi DR, Ediga RK, Sisapuram Y. Synthesis, in-Vitro antioxidant aActivity and in-silico prediction of drug likeness properties of a novel compound: 4-(3,5-Di-tertbutyl-4-hydroxybenzylidene)-3-methylisoxazol-5(4H)-one. J Appl Pharm Sci, 2019; 9(09):105-110. 